\title{
Hardware implementation of auto switching and light intensity control of LED lamps
}

\author{
S. Singh and S. Bhullar
}

\begin{abstract}
This paper presents energy efficient lighting control architecture for street lights. The system utilizes auto intensity control technology to be implemented on street lights to make it a smart street lighting system. The proposed system consists of LED Lamps, infrared transmitter and receiver, NE555 timing IC, SPDT relays, PV panel, etc. Intensity of street lamps is controlled depending upon the movement of vehicles on the road. When any vehicle passes on the road, increases the light intensity of lamps for a few seconds and automatically set in previous position when a vehicle passes out. Also manpower is totally eliminated by the use of auto switching of street light. This is the best and cheapest method for saving energy and also for possible reducing lighting pollution. The PV system is used for charging the batteries, the power of which is used during the night and grid source is also used as a backup of our system when sometimes PV Off-Grid goes faulty.
\end{abstract}

Index Terms - Energy efficient system, Smart Street lighting, LED, HPS, CRI, NO, NC, auto light intensity control, PV offGrid, Light pollution.

\section{INTRODUCTION}

$\mathrm{T}$ HE main scope of outdoor lighting is the extension of an acceptable human life quality consists of i.e. accessibility of social activities, traffic safety during night, crime prevention and human behavior during dark period of the day. The main purpose of road lighting is to make people, vehicles and objects on the road visible.

In these days, HPS Lamp is widely used for street lighting system which produces yellow light with low CRI, short life up to 5000 hrs, contains a lead element. The main limitation is that it takes some time for initial starting. It consumes more power as compared to other lighting lamps. [1]

Today's latest technology LED Lamps which have high CRI nearly greater than 80 , produce white cool light, long life up to 50,000 hrs, contains no lead element, less ignition time, less maintenance and no effect of switching on its life. It consume less power as compared to HPS, but its initial cost is high which is one of the limitation of LED [2]. We can save a lot of energy and reduce tons of carbon dioxide emissions per year. Conventional lighting systems are working on bi-level approach either ON or OFF. When ON, it operates on its rated power and there is no control to adjust its light intensity according to the availability of traffic on roads. The light intensity control system is introduced to reduce energy consumption inherent to

S. SINGH, is with Thapar University, Department of Electrical and Instrumentation, Patiala, India (e-mail: satwindersinghsekhon@hotmail.com).

S. BHULLAR, is with Thapar University, Department of Electrical and Instrumentation, Patiala, India (e-mail: suman.bhullar@gmail.com). conventional lighting system. The PV panel is used to charge the battery whose power is used during the night for street lights[3]. In this work system power is used from both grid source as well as from a PV system. Analysis between HPS and LED lamp.

Objective: The objective of the work is to control energy consumption, reduction of $\mathrm{Co}_{2}$ emissions and to obtained sustainable system.

\section{SYSTEM ARCHITECTURE}

The system combines advanced and traditional controlling features. The proposed system minimizes the energy consumption for the benefit of users and environment friendly.

The system comprises of Infrared transmitter, infrared receiver, PV Panel, transformer, NE-555 timing IC, SPDT relays, LED Lamps, rectifier and filter unit, LDR, 7805 voltage regulator, BC 547 transistor.

\section{A. Infrared transmitter}

Infrared transmitter used white infrared LED, timing IC in a stable mode where it can operate as an oscillator and produce $38 \mathrm{KHz}$ signal [4] which continually fall on the receiver.

\section{B. Infrared receiver}

TSOP 382 sensor is used as a receiver in the hardware model project, which is placed on opposite side of transmitter near the street light tower. Output of TSOP382 will be LOW when no signals falls on it and the output will be $\mathrm{HIGH}$ when $38 \mathrm{KHz}$ infrared rays falls on it [5].

\section{PV Panel}

$12 \mathrm{~V}, 12 \mathrm{~W}$ PV panel is used for charging the $12 \mathrm{~V}, 2.5 \mathrm{Ah}$ batteries that power are used at night for street lights.

\section{Transformer}

It is used stepping down the $220 \mathrm{~V}$ into $12 \mathrm{~V}$ to operate the entire circuit.

\section{E. NE 555 Timing IC}

This IC is used in two modes in this circuit, one is a stable and another is mono-stable mode. A stable mode is used in transmitter circuit and Mono-stable mode is used for timing delay that depends upon the sensitivity of traffic by a sensor on the road. [6]

\section{F. SPDT Relay}

It is an electromagnetic device which is used to isolate two circuits electrically and connect them magnetically. They 
are very useful devices and allow one circuit to switch another one while they are completely separate. They are often used to interface an electronic circuit to an electrical circuit which works at very high voltage. When the relay is energized they are working in $\mathrm{NC}$ mode and during deenergized in NO mode and COM pin is always connected with a 5V supply [7].

\section{G. LED Lamps}

They are used for lighting during the night in street lights. In this model 8 LED's are used which are connected in parallel across supply and each having a rating of $1 \mathrm{~W}$.

\section{H. Rectifier and filter unit}

Full wave rectifier is used to convert the ac output of the transformer into DC. The output of rectifier contains ripples which can be further removed by capacitor as a filter unit and hence pure DC is obtained. [8]

\section{Light Dependent Resistor}

It is a device which offers resistance in response to the ambient light. Its resistance decreases when light falls on it and vice versa. In the absence of light, LDR exhibits a resistance of the order of mega-ohms, which decrease too few hundred ohms in the presence of light [9]. It can acts as a sensor, since a varying voltage drop can be obtained in accordance with the varying light.

\section{J. 7805 voltage regulator IC}

It is used in various electronic circuits where we need $5 \mathrm{~V}$ supply. An IC is designed as fixed voltage regulator and with adequate heat sinking; it can deliver output current in excess of 1A. [10]

\section{K. BC 547 transistor}

The transistor is 3 pin devices which are used as a switch in hardware model.

\section{Battery and grid source interface through relay} based circuit

We use the power form both grid sources as well as from a battery. In cloudy days or during winter when sun light is not available for many days or due to any other reason batteries are not charged properly, then we can use grid source.

An automatic interface circuit between grid source and battery is designed. $12 \mathrm{~V}$ relay is used which is excited through the secondary of transformer but that is ac which is convert into $\mathrm{dc}$ by the use of diode. Capacitor is used to remove the ripples [11]. When the grid is supplying power then the relay is excited and cut off the supply from battery side. When power from grid side is switched off, then relay de-energized and the battery is used as a source for street lighting.

\section{CIRCUIT DIAGRAM}

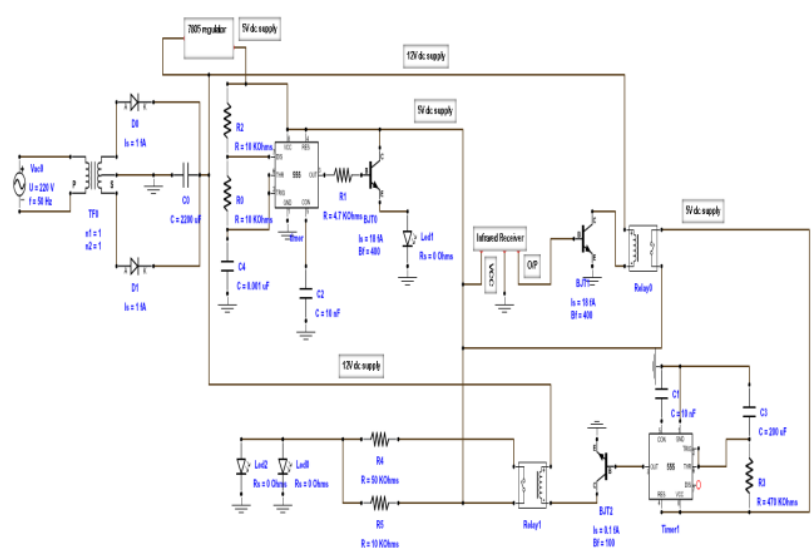

Fig. 1. Auto light intensity control of LED Lamp

\section{A. FLOW CHART}

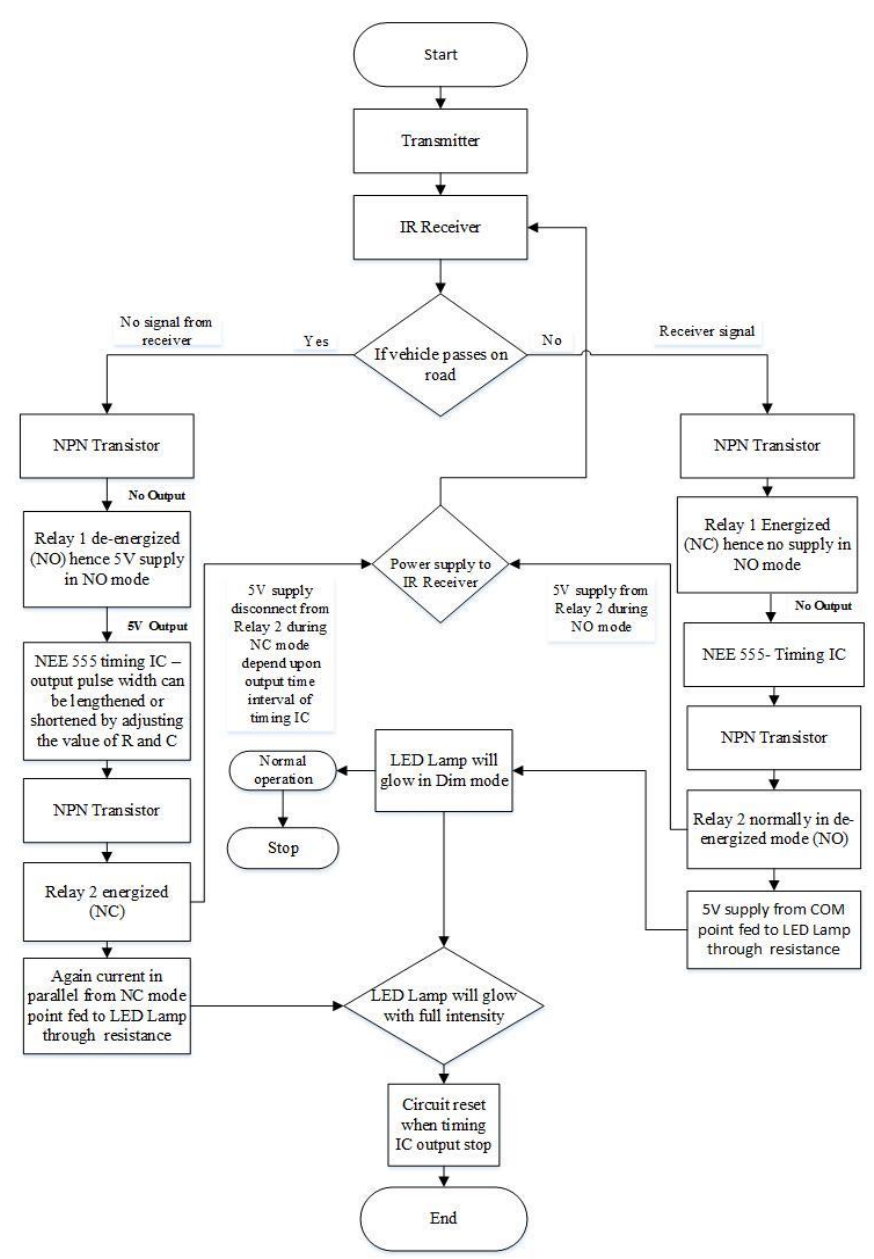

Fig. 2: Auto light intensity control of LED Lamp

The above flow chart explains the operation of controlling of intensity of LED Lamps. The transmitter generates 38 $\mathrm{KHz}$ signal which is falling on the receiver [12]. When there is no traffic on the road, then transmitter signal fall on the receiver continuously and the output of the receiver will be high then relay 1 is energized and it starts operating in NC mode. During this period, the power to LED Lamps by adding resistance in series is supplied through second relay from COM pin which is connected with $5 \mathrm{~V}$ and LED glows in dim mode. 
When any vehicles pass through the road, then the receiver detects it and its output goes low for that instant only relay 1 gets de-energized and starts operating in NO mode.

When relay 1 starts operating in NO mode, and then timing IC is also triggered. It starts working as a short pulse generator [13]. With the output of timing IC, relay 2 gets energized. The input supply to the infrared receiver is fed from NO mode of the relay. So, when relay 2 is energized and starts working in NC mode, at that time, this supply also cuts off and current in parallel again fed to LED lamps which increase its intensity and starts its operation in full mode. The time interval of full mode depends upon NE 555 timing IC. After a few seconds, the LED Lamps again starting glow in dim mode when a vehicle passes out. In this way, the intensity of LED lamps is controlled which can save energy and reduces light pollution.

\section{AUto SWITCHING ON STREET LIGHT}

Auto switching of the street light is used to eliminate the manpower. By using the auto switching system of Smart Street lighting energy consumption can be reduced because manually operates lighting system are not switched ON earlier before sunset and also not switched OFF properly even the sunlight comes[14]. By implementation of auto switching system, maintenance and energy cost can be reduced and community satisfaction will be higher.

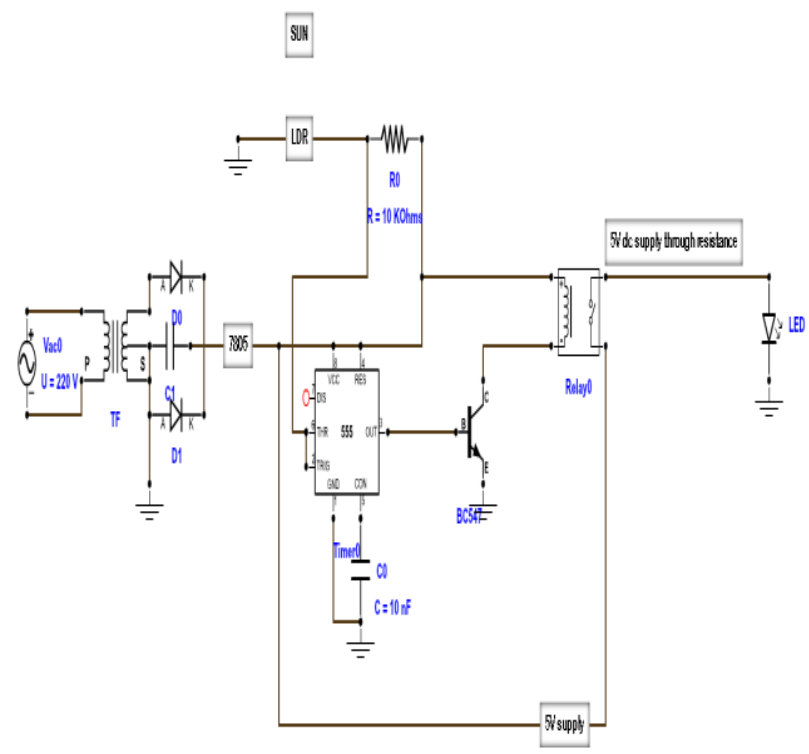

Fig. 3: Auto switching of Smart Street light

During the day: The sun rays continue falling on LDR and its resistance decreases, which results in an increase of the voltage at pin 2 of the IC 555. IC 555 has got comparator inbuilt, which compares between the input voltage from pin 2 and 1/3rd of the power supply voltage [15]. The input rises above $1 / 3^{\text {rd }}$, output is set LOW and the relay gets deenergized. During the de - energized mode, the relay will operate in NO mode; hence there is no supply in NC mode. So, the street light will not turn ON at day time.

During the night: At night time, when no light falls on LDR i.e. its resistance increases, which results in a decrease of the voltage at pin 2 of the IC 555, then the timing IC output goes $\mathrm{HIGH}$ and the relay gets energized. It starts operating in NC mode [16]. Hence, the power supply from the COM point of relay gets connected with street light. As a result it will switch ON during the night. Next day when the sun rises, then light will turn OFF automatically.

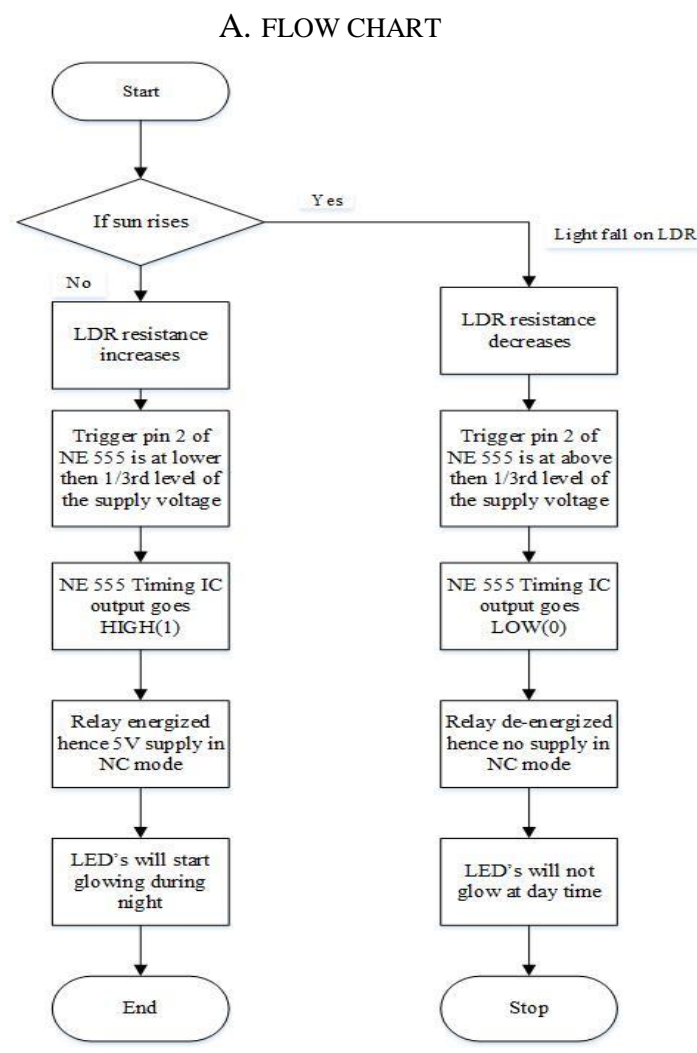

Fig. 4: Auto switching on the street light

\section{WAVEFORMS OF CIRCUIT COMPONENTS}

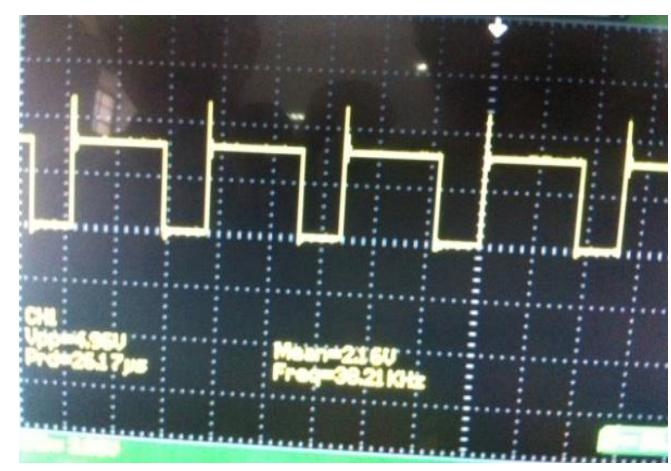

Fig. 5: Output waveform of NE555 in transmitter circuit

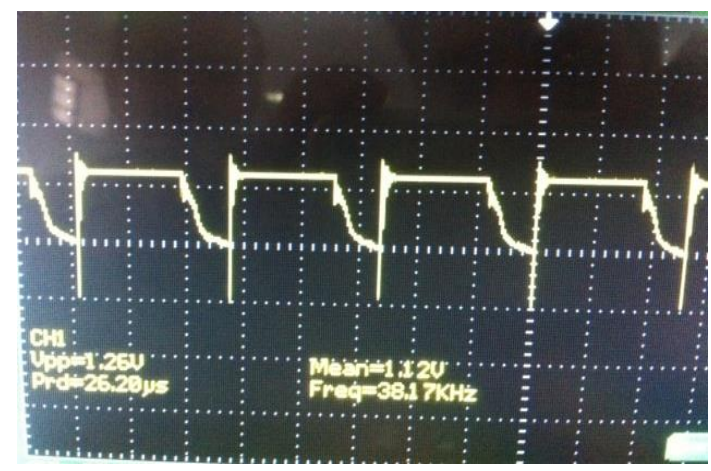

Fig. 6: Infrared LED waveform in dim mode 


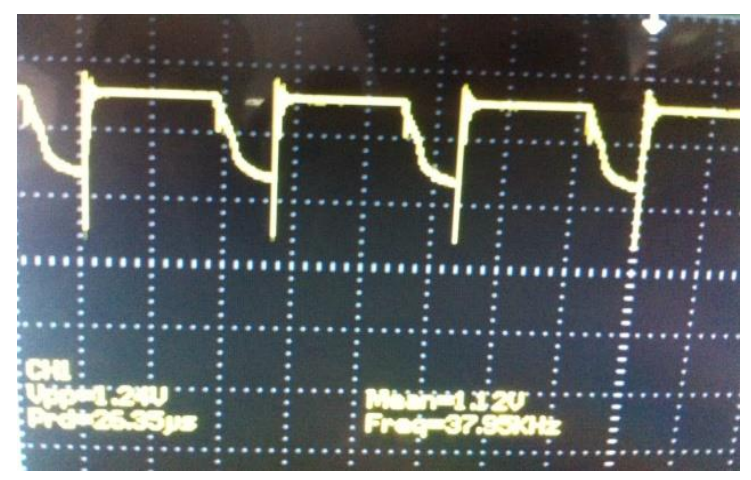

Fig. 7: Infrared LED waveform in Full mode

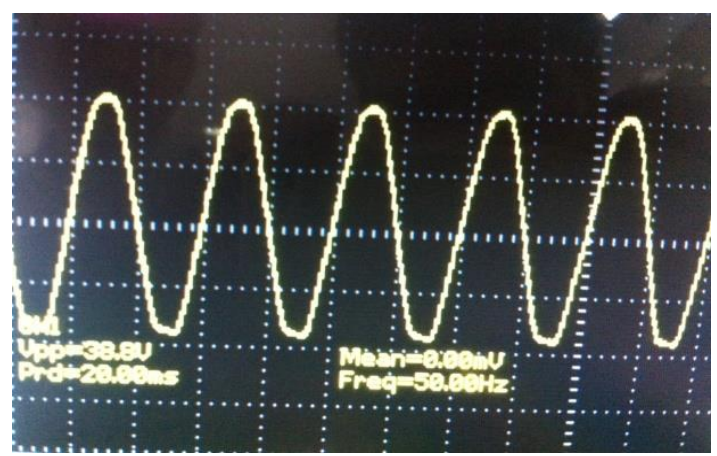

Fig. 8: Transformer output waveform

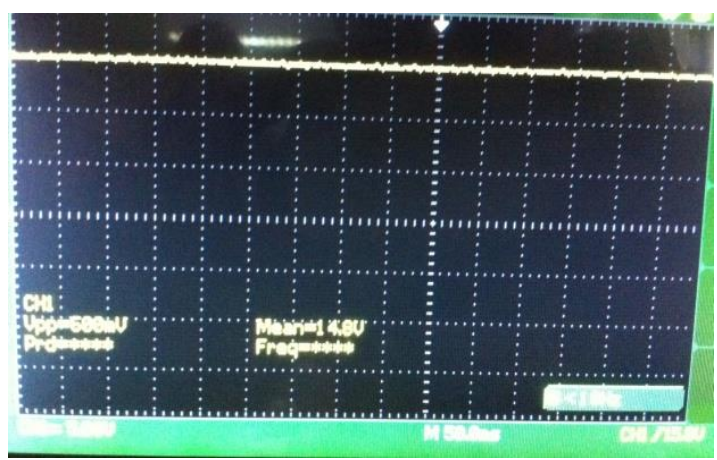

Fig. 9: Rectifier output waveform

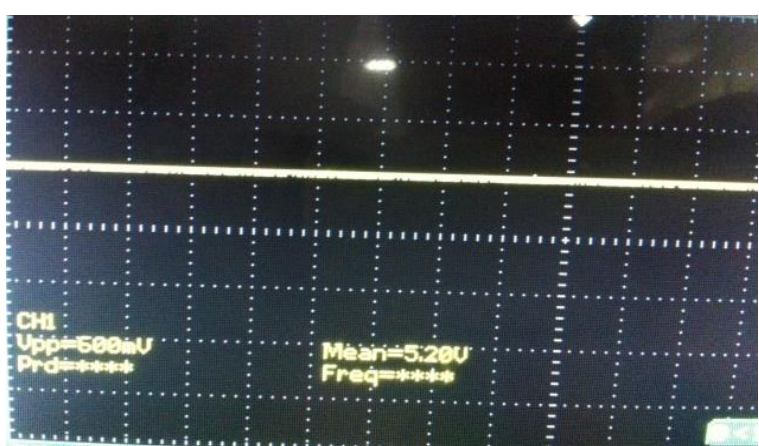

Fig. 10: 7805 transistor output waveform

\section{SYSTEM IMPLEMENTATION}

Auto switching and light intensity control of LED Lamps aim to modernize infrastructure of traditional wired system, currently exercised for outdoor lighting systems. This method has low cost, less maintenance and can be implemented easily. [17] $>\quad$ View of implemented system model in different modes

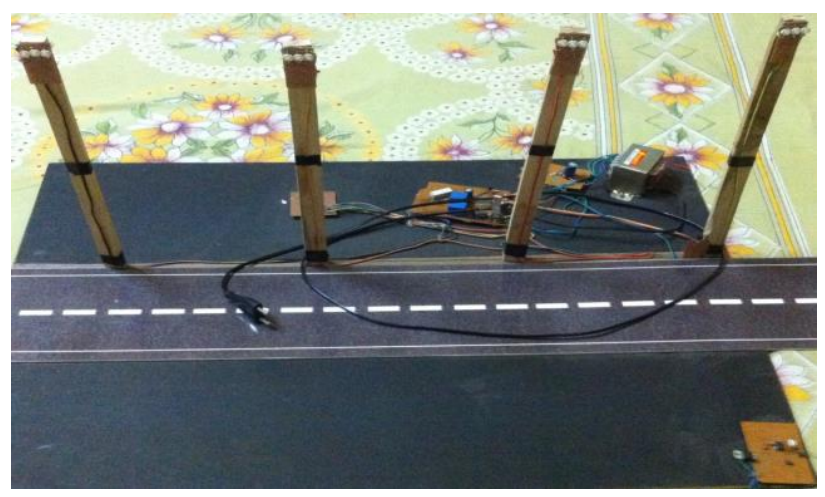

Fig. 11: Normal view

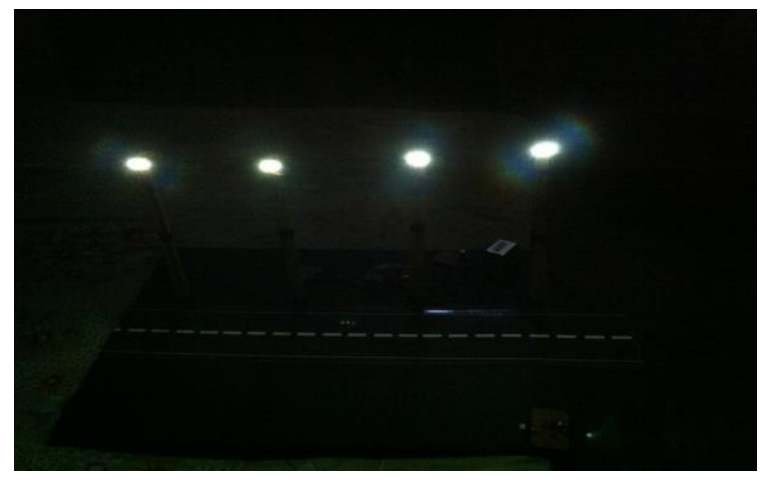

Fig. 12: LED Lamp glow in Dim Mode

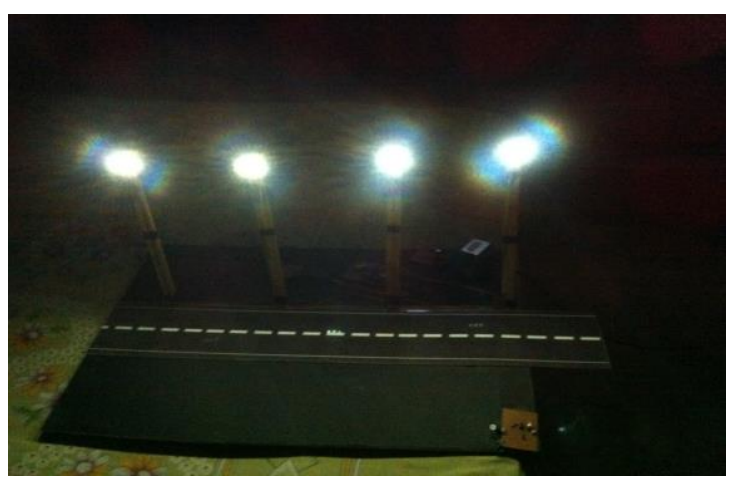

Fig. 13: LED Lamp glow in Full mode

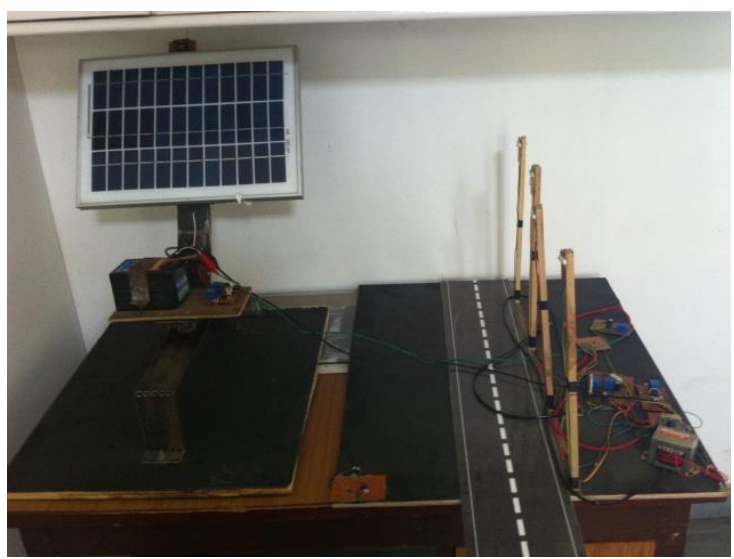

Fig. 14. Complete Hardware Setup 


\section{POWER CONSUMPTION BY LED LAMPS}

Load current consumed by LED Lamps during Dim mode = $0.12 \mathrm{~A}$.

Load current consumed by LED Lamps during Full mode = 0.26A.

Battery voltage $=12 \mathrm{~V}$.

Power $=$ VI.

So, Power consumed during Dim mode $=12 \times 0.12 \mathrm{~A}=$ $1.44 \mathrm{~W}$.

Power consumed during Full mode $=12 \times 0.26 \mathrm{~A}=3.12 \mathrm{~W}$.

So, from the above calculations it shows that we can save energy more than $50 \%$ and reduce $\mathrm{Co}_{2}$ emissions, if we use this model.

\section{CONCLUSIONS}

This paper is aimed at designing and implementation of an automatic street lighting system where in the street lights that are not required through the night can be dimmed. Additionally, the ambiance of light is checked and lights are turned ON when it is dark and turned OFF during the day.

The proposed system is designed to eliminate the manpower and reduce energy consumption of outdoor premises and demonstrated by developing a prototype to control street lights. The system reduces the energy consumption for the benefit of user and environment friendly [18].

\section{ACKNOWLEDGEMENT}

The author would like to acknowledge Faculty of Electrical and Instrumentation Engineering, Thapar University, Patiala in supporting this work.

\section{REFERENCES}

[1] Sanjana, "Solar Powered traffic sensitive automated LED street lighting system", M.E Thesis, Dec 2012.

[2] W.L. Chee," Modular Intelligent Control System", B.E Thesis, May 2011.

[3] M. Ali., M. Orabi, E. Abdelkarim, J.A.A. Qahouq, A.E. Aroudi, "Design and development of energy-free solar street LED ligh system," IEEE PES Conference on Innovative Smart Grid Technologies - Middle East, pp. 1- 7, 17-20 Dec. 2011.

[4] A. Sanjana," Solar Powered traffic sensitive automated LED street lighting system", M.E Thesis, Dec 2012.

[5] M. Castro, A.J. Jara, A.F.G. Skarmeta, "Smart Lighting Solutions for Smart Cities," 27th International Conference on Advanced Information Networking and Applications Workshops, pp.1374 1379, 25-28 March 2013.

[6] G.M. Ereu, J.O. Mantilla, "A Methodology to Determine Electrical Energy Consumption in Street Lighting Systems," IEEE/PES on Transmission \& Distribution Conference and Exposition: Latin America, pp. 1-5, 15-18 Aug. 2006.

[7] H. Rohaida, O. Zulkifli," Automatic Street Lighting System for Energy Efficiency based on Low Cost Microcontroller", IJSSST, Vol.13, No.1, 2012 .

[8] J.D.Lee, K.Y. Nam, S.H. Jeong, S.B. Choi, H.S. Ryoo, D.K. Kim, "Development of Zigbee based Street Light Control System," IEEE PES on Power Systems Conference and Exposition, pp. 2236- 2240, Oct. 29-Nov. 12006.

[9] L. Lian, L. Li "Wireless dimming system for LED Street lamp based on Zigbee and GPRS," 3rd International Conference on System Science, Engineering Desion and Manufacturing Informatization, Science, Engineering Design and Man
vol. no. 2, pp. 100-102, 20-21 Oct. 2012 .

[10] D.V. Pushpa Latha," Simulation of PLC based Smart Street Lighting Control using LDR', International Journal of Latest Trends in Engineering and Technology, Vol. 2 Issue, July 2013.

[11] M. Reinhard, Reiner Andreas,"'An energy efficient pedestrian awạe Smart Street Lighting system", International Journal of Pervasive Smart Street Lighting system", International Journal of Pervasive

[12] R.P. Pantoni, D. Brandao, "A geocast routing algorithm intended for street lighting system based on wireless sensor networks," 9th IEEE/IAS International Conference on Industry Applications, pp. 16, 8-10 Nov. 2010.

[13] M. Popa and A. Marcu," A Solution for Street Lighting in Smart Cities", Carpathian Journal of Electronics and Computer Engineering, Vol. 5, pp. 91-96, 2012.
[14] R. Priyasree, R. Kauser, "Automatic Street Light Intensity Contro and Road Safety Module Using Embedded System", Internationa Conference on Computing and Control Engineering, 12-13 April 2012.

[15] A.A. Siddiqui, A.W. Ahmad, H.K. Yang, C. Lee, "ZigBee based energy efficient outdoor lighting control system," 14th International Conference on Adv
19-22 Feb. 2012.

[16] M. Ali, M. Orabi, M.E. Ahmed, A. El-Aroudi, A single stage SEPIC PFC converter for LED street lighting applications, Power and Energy (PECon), 2010 IEEE International Conference on, Nov. 29 2010-Dec. 12010 , pp.501-506.

[17] Yoshiura, N.; Fujii, Y.; Ohta, N., "Smart street light system looking like usual streetlights based on sensor networks," Communication and Information Technologies, 2013 13th International Symposium on, pp. 633,637, 4-6 Sept. 2013

[18] N. Zotos, C. Stergiopoulos, K. Anastasopoulos, G. Bogdos, E. Pallis, C. Skianis, "Case study of a dimmable outdoor lighting system with intelligent management and remote control," Telecommunication and Multimedia (TEMU) 2012 International Conference on, 43,48, July 30 2012-Aug. 12012.

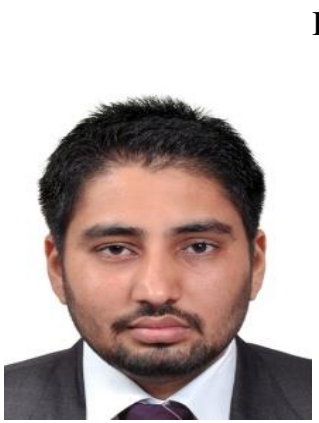

\section{BIOGRAPHIES}

SATWINDER SINGH was born in 1988 $\mathrm{He}$ received his Diploma in Electronics and Telecommunications Engg. From PSBTE \& IT Chandigarh in 2008 and Bachelor Degree in Electrical and Electronics Engg. From Punjab Technical University, Jalandhar in 2012. Recently, he is completed Master's degree in Power Systems from Electrical and Instrumentation Department at Thapar University, Patiala and Researched on the topic of the Smart Street Lighting System.

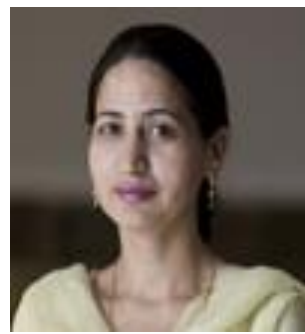

SUMAN BHULLAR was born in 1976. She received her Bachelor degree from Punjab University, Chandigarh and Masters Degree in Electrical Engineering from Punjab Technical University, Jalandhar in 1997 and 2001 respectively. Presently, she is an Assistant Professor and Pursuing Ph.D in Electrical and Instrumentation Department, Thapar University, Patiala. 